\title{
Implications of customer value perceptions for the design of electricity efficiency services in times of smart metering
}

\author{
Antonia Albani $^{1}$ (D) Yannic Domigall $^{1}$. \\ Robert Winter ${ }^{1}$
}

\begin{abstract}
Smart meters are the backbone of modern electricity metering and an important enabler of reaching energy efficiency targets. The implementation of new metering infrastructure is, however, making little progress and is often focused on technical aspects only. Additionally, existing smart metering information systems do not yet exploit the possibilities to optimally support customers in their electricity savings activities. Knowing customer preferences is absolutely essential for the effectiveness of energy efficiency measures and, as a consequence, for realizing the economic value of smart metering technology. The presented research contributes to the field by identifying customer value perceptions concerning new smart meter services in the retail electricity market in Switzerland. Founded on a choice-based conjoint analysis with a data sample of more than 1500 respondents from three Swiss regions, five customer segments with different preferences are identified. With the exception of the comfort-oriented customer segment, the other four segments are comprised of customers who are willing (1) to pay for smart meter services and (2) to change their behavior to save electricity. Based on the identified customer value perceptions, implications for the design of smart meter-based energy efficiency services are elaborated.
\end{abstract}

Keywords Electricity efficiency services - Smart metering · Customer value perceptions

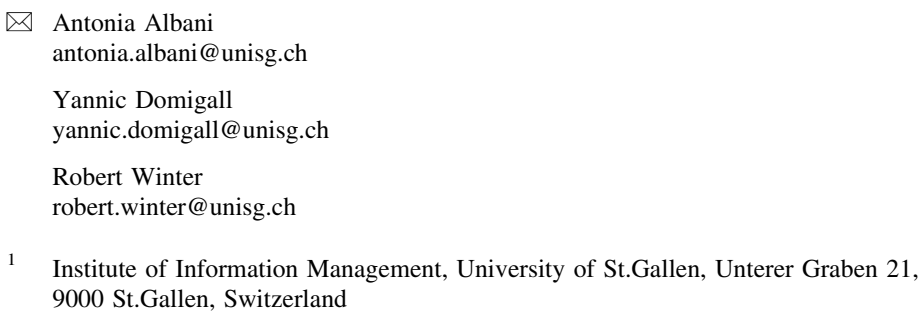




\section{Introduction}

Presently, there are still barriers that limit the rollout speed of smart meters in most European countries (Muench et al. 2014; Römer et al. 2012). A slow rollout speed reduces the realization of the energy efficiency potential and, therefore, threatens the intended reduction of $20 \%$ of the energy consumption by 2020 in the European Union (Directive/27/Eu 2012). Smart meters are central gateways that are located on the customer's site and that support two-way communication. Thus, advanced metering infrastructure connects consumers and other energy systems' parties by using information and communication technologies (Römer et al. 2012). Through smart meter technology and supporting information systems, metering processes can be improved, customer specific consumption data can be systematically analyzed, and innovative products like regional load profiles or energy management planning services can be offered [see e.g., (Flath et al. 2012)]. An important field where smart meter technology and their supporting information systems can provide additional benefit is the area of energy savings. As the European Union announced in 2011, enabling customers to save energy is one of the most important aspects to implement the ambitious energy efficiency targets (European Commission, 2011). The aspect of applying information systems for environmental sustainability gains more and more attention and has among others been addressed in a special issue of the MISQ journal (Malhotra et al. 2013). The increase of energy efficiency beyond what engineering can do is, among others, also one goal of the young research area of Energy Informatics (EI) (Goebel et al. 2014). Through information and communication technology, information systems can be developed that allow, e.g., utilities to influence the customer's consumption behavior or enable individuals to better measure and understand their energy consumption and therefore react accordingly. As an example, Loock et al. (2013) introduce an information system designed to encourage electricity consumers to reduce their energy consumption and show that the savings achievable by goal-setting functionalities and feedback loops are ultimately worth the effort. Over recent years, several information systems based on smart meters have been proposed that aim to reduce end consumers electricity consumption. Such smart meter information systems range from home displays and Internet platforms to smart phone apps and more. According to Nachreiner et al. (2015), such "smart meter systems have been introduced with the expectation that, with the help of feedback, electricity consumption may be reduced substantially. Regrettably, the reduction of consumption often was not as high as expected (Darby 2006; Ehrhardt-Martinez et al. 2010; Fischer 2008; Mack 2007)”. Technologybased enablers are useless as long as customers do not react to the offered potentials and incentives. Due to this situation, it is essential for electricity providers to understand customer value perceptions of services that are based on smart metersalso called smart meter services_-and to be able to offer adequate services by means of smart meter information systems. The necessity of understanding customer value perceptions of smart meter services is in line with Goebel et al.'s (2014) general request that future energy informatics research needs to explore the behavior of people and organizations that interact with information technology in this domain. 
The study presented in this article aims at understanding the customer value perceptions of smart meter services and the conditions under which customers are willing to change their behavior in order to increase the efficiency of the electricity use. Based on these insights implications for the design of smart meter-based energy efficiency services are elaborated.

The effect of benefits and sacrifices on the perceived value of services has been investigated in several studies. For example, Kim et al. (2007) introduce a structural equation model for mobile Internet services, in which usefulness, enjoyment, technicality, and perceived fee are used to build and test hypotheses about their perceived value and their adoption intention. The value-based adoption model of technology by Kim et al. (2007) has been re-used, for example, in the domain of social networks by Kuan-Yu and Hsi-Peng (2011), in which the authors combine the said model with continuous use. In the energy domain, the impact of benefits and sacrifices has also been used to argue the perceived customer value of smart meter services (Kaufmann et al. 2013). Kaufman et al. conduct an explorative study by modeling the importance of perceived customer value of smart metering in Switzerland. The study presented in this article is based on Kaufmann et al.'s explorative work (Kaufmann et al. 2013) and is also focusing on the Swiss market.

The Swiss market is characterized by private customers who cannot yet choose their electricity providers and by an energy policy that has not placed an emphasis on the implementation of smart metering thus far. "The lack of a mandatory smart meter rollout in Switzerland makes it possible to study customers' value perceptions of and willingness to pay for smart metering without potential biases that result from energy policy measures aimed at the diffusion of smart metering" (Kaufmann et al. 2013). Nevertheless, the Swiss market is also subject to several restrictions, such as uncertainty over smart meter implementation. However, following the argumentation of Kaufmann et al. we agree with their conclusion that Switzerland is a country well suited for such a study (Kaufmann et al. 2013). Furthermore, energy efficiency is one of the essential measures of the Swiss government for implementing the "Energy Strategy 2050", according to Becker et al. and a smart meter rollout appears to be a plausible scenario for Switzerland in the near future, because such a rollout might be viable from an economic perspective (Baeriswyl et al. 2012; Becker et al. 2012). As a consequence, Switzerland seems very suitable for studying customer preferences concerning services based on smart meters that may enable efficiency measures.

In the presented study we present new smart meter services for customers and identify five customer segments with different preference structures regarding smart metering. The applied choice-based conjoint analysis is based on a relevant amount of valid data sets (1594 valid data sets in total) from three different regions in Switzerland. The proposed services and segmentations allow us to understand and discuss the different customer perceived values of the presented efficiency measures. Based on these results, we elaborate on implications for the design of smart metering-enabled services in the electricity domain and their supporting information systems.

Our paper is structured as follows: The research approach used in this study is introduced in Sect. 2. The survey, the sample, and the choice-based conjoint 
analysis, which includes the structure of the attributes of the conjoint analysis, are described in detail. In Sect. 3, the empirical analysis of the result sets and the identification of customer segments are illustrated. Based on these results, the implications for a successful design of smart meter-based energy efficiency services in Switzerland are elaborated in Sect. 4. In Sect. 5, the limitations of the study are discussed and directions for future research are outlined.

\section{Method}

\subsection{Choice-based conjoint analysis}

In order to develop an in-depth understanding of customer preferences regarding services in the retail electricity market in Switzerland, we conducted a choice-based conjoint analysis (Louviere 1988). The choice-based conjoint analysis has the advantage that the willingness to pay of every respondent may be calculated for each service and each attribute. Without using arbitrary selection mechanisms, the choice-based conjoint analysis allowed for a reduction of the number of ideas for new services that foster the efficient consumption of electricity. With the survey, we were able to obtain data for different product-service bundle preferences from different customer groups (e.g., customers of different energy providers), which additionally contributed to a better understanding of the customer preferences. The questionnaires were analyzed by using statistical methods and simulation techniques in order to identify the most useful services. In a first step, the conjoint part-worth values were calculated. These part-worths represent the customer's preference for a specific product-service bundle compared to other product-service bundles. In a second step, we hypothesized that fundamental differences between customers groups may occur. For the further analysis of the groups, we suggested the use of latent class analysis. According to Magidson et al. (2003), latent class analysis is currently the best way to identify homogeneous segments of customers within choice-based conjoint data. A possible simulation scenario with the generated data was, for instance, a ceteris paribus price increase in a market simulator. Furthermore, we were able to calculate price sensitivities based on a broad basic population. Through the analysis and understanding of the preferences of the customers regarding the new smart meter services, we were able to derive respondent clusters that had a similar willingness-to-pay structure. The collection of the data used for the analysis of the surveys was gathered in cooperation with three different electricity providers in Switzerland.

\subsection{Survey and sample}

The choice-based conjoint analysis comprised 9084 choice tasks. The paper-based questionnaire was sent to 15000 potential participants in ten different versions to guarantee a higher statistical significance. The invited participants were intentionally selected to ensure that different age groups and genders are as well represented in the study as much as possible in comparison to the overall population. The 
responses were collected in fall and winter 2013. The return rate of the questionnaires was $10.6 \%$. After deleting the unusable responses, a total of 1594 questionnaires remained in the net sample. We included socio-demographic questions in our questionnaire in order to obtain further information about the respondents. The questions were related to the age of the respondents, the number of persons per household, the number of rooms in the household, the respondent's highest level of education, their electricity supplier, and their mix of energy sources.

The choice-based conjoint analysis is a decompositional analysis method used in market research and is part of the category of interdependence analysis; the aim of this analysis is to identify presumed relations in a data set (Hair et al. 2009). The basic idea of a choice-based conjoint analysis is to subdivide a product-service bundle into its attributes and to show different combinations of the characteristics of the attributes to customers in so-called choice sets. The customers have to make a trade-off decision between the presented bundles, which are also called stimuli (Green and Srinivasan 1978; Louviere 1988). The choice-based conjoint analysis is broadly used for testing the potential of new products or services in the market (Dellaert et al. 1996; Hair et al. 2009). A major advantage of choice-based conjoint analysis is that customers do not have to quantify the individual value of each attribute (part-worth) and instead simply choose their preferred product-service alternative (Messerschmidt et al. 2010). However, even though the respondents chose their preferred product service alternative in the questionnaire, this choice remains hypothetical, because the preferences are only stated and not observed purchases.

Additionally, the choice-based conjoint analysis places some constraints on the attributes and their characteristics, which need to take into account:

- Relevance: the attributes chosen need to be relevant to the customer decision

- Independence: the attributes need to be independent from one another; meaning none of the attributes can be part of another attribute

- Symmetry: all attributes have about the same amount of characteristics in order to prevent imbalances between the attributes

- Characteristics: the spread between the characteristics needs to cover the broad variety of the attributes

In order to identify the essential attributes and their characteristics for the questionnaire a structured literature review as presented in vom Brocke et al. (2009) was conducted. In a first step, relevant journals and conference proceedings were identified. The literature was then collected by using databases such as, for example, EBSCOhost and systematically analyzed. The service areas identified in the literature review built the basis for the following steps, where potential service areas were identified by interviewing experts and customers of related industries. To ensure that the interests and ideas of customers were optimally understood and discussed, a group moderation creativity method, namely the Open Space Method according to Owen (2008), was applied. In total, 19 experts-electricity professionals from several parts of the electricity supply chain in Switzerland, such as trading, marketing, electricity generation, grid services, and sales-as well 
as 33 customers from three different electricity providers in Switzerland participated. Based on the literature review, the active cooperation of the experts and customers due to the highly relevant topic, and taking into account the constraints on the attributes and their characteristics placed by the choice-based conjoint analysis, relevant areas for potential future services and the attributes have been identified. The resulting attributes and their characteristics used in the questionnaire are listed in Table 1.

Six different pricing options were included in the questionnaire. Four of these formed the characteristics of the tariff model, as shown in Table 1.

The high and low tariff (also known as time-of-use tariff) as well as the simple tariff became part of the tariff model, because they have been broadly used in Switzerland over the last decades. The peak pricing tariff was especially successful in California (Faruqui and George 2005). Compared to the time-of-use tariffs, the critical peak pricing was found by Faruqui and Sergici to have a much bigger impact on the peak load reduction in almost all the 14 experiments (Faruqui and Sergici 2008). Apart from the peak pricing tariff, the real time tariff was also considered by the experts and customers as very relevant and was therefore added as a tariff characteristic to the questionnaire. Since we used fix prices corresponding to the tariff models, it is no longer possible to say whether a respondent chose the prices or the tariff model. However, the prices make it easier for the respondents to

Table 1 Attributes and related characteristics

\begin{tabular}{ll}
\hline Attributes & Characteristics \\
\hline Tariff model & High/low tariff (20 Rp. $\left.{ }^{\mathrm{a}} / 12 \mathrm{Rp} . \mathrm{kWh}\right)$ \\
& Peak pricing (18 Rp./90 Rp. kWh) \\
& Simple tariff (19 Rp. kWh) \\
& Real time tariff (5 Rp.-25 Rp. kWh) \\
& Online portal \\
Electricity savings support & Selling electricity saving products on home page \\
& Hints regarding electricity savings on the bill \\
& No support \\
& Consumption display \\
Electricity monitor & Ambient display \\
& Mobile-app or home page \\
& No visualization \\
& Telephone, post and e-mail \\
Communication channel & Only e-mail and online portal \\
& Personal consultant \\
& 20 Fr. \\
Basic fee per month & 22 Fr. \\
& 24 Fr. \\
& 26 Fr. \\
\hline
\end{tabular}

a 100 Rp. = 1 Fr. (Swiss Franc); 1Fr. is approximately worth $1 \$$ or $0.89 €$ 
understand a given tariff. Furthermore, we used an amount for the simple tariff that is quite common in Switzerland and adjusted the other three tariffs to yield exactly the same total amount for an average standard load profile customer. The starting point was a standard load profile customer, which is the basis for all grid optimizations. Without any behavioral changes regarding the standard load profile, a customer may not profit from a tariff change due to regulation (StromVG, article 19, section 2c ff.). Therefore, customers can benefit from the new tariffs if their load profiles significantly differ from the standard load profile or if they are willing to change their behavior.

The attribute 'electricity savings support' was included in the questionnaire in order to provide different options for the respondents to obtain information about energy efficiency measures. Possible channels for electricity saving support are web portals, home pages or the electricity bill.

The visualization of consumed electricity was found to have a major impact on the effectiveness of the tariff in almost all experiments reported in the literature (Darby 2006; Faruqui and Sergici 2008). Due to this fact, 'electricity monitor' was added as an attribute to the questionnaire. The attribute characteristics of the visualization appliances were explained to the respondents in the questionnaire by means of a textual description, and also pictures of the three visualization appliances were provided. The consumption display is an appliance that shows the currently consumed electricity as well as the sum of the consumed electricity from the previous few days. The ambient display visualizes the currently consumed electricity by comparing it to the consumption average and then glowing in a blue (low current consumption) or red (high current consumption) light. Electricity monitor possibilities (for example, mobile-app or homepages) were also considered as highly relevant.

Furthermore, communication channels through which the communication between customers and the enterprise takes place played an important role according to the group sessions. Traditional channels are, for example, phone or service centers, while a more recent addition is the Internet.

Different compositions of the aforementioned attributes may result in different metering services being offered to customers. Since the benefit of these metering services varies among the customers, one can assume that the willingness to pay for such services differs. The basic fee per month attribute allows for calculating the customers' willingness to pay. ${ }^{1}$ With this calculation, it is possible to quantify the choice-based conjoint analysis values with monetary values. The basic fee for the electricity provision of the three electricity providers that supported our study was approximately $20 \mathrm{Fr}$. per month at the time the questionnaires were sent to their customers. From our experience in earlier studies, price jumps of 2 Fr. resulted to be

1 The amount of the basic fee per month differs significantly between the attributes, while the different tariff options themselves sum always up to the same amount for a standard load profile customer. A customer can therefore only be better off with a given tariff model, if he is willing to change his behavior significantly compared to the standard load profile of a customer. We do therefore not have two pricing attributes in the same questionnaire but one pricing attribute and one tariff attribute that allows to check the willingness to change to a new tariff model. The utility changing costs can therefore be directly used to identify the customers' willingness to pay (calculated in comparison to the basic fee). 
the most realistic for the customers. Therefore, 20, 22, 24 and 26 Fr. were added as characteristics for the basic fee attribute, representing real price options for possible service configurations.

The statistical quality of choice-based conjoint experiments is highly dependent on the number of attributes used. The more attributes and characteristics used, the lower the statistical quality for a given sample size. We therefore decided to use five attributes with three to four characteristics each in order to reach a high statistical significance. Based on the attributes and their characteristics introduced above, six fixed choice sets, including three stimuli each, were generated and presented to the respondents. We used a near-symmetrical design with three to four characteristics per attribute, which were selected with the advanced design module of CBC/Web of the Sawtooth SSI Web software. In order to increase the statistical survey quality, we generated ten versions of the questionnaire with six choice sets each. Thus, we had 60 choice-set versions.

We define a stimulus as a combination of service attributes that can be paired with a service and offered to customers on the market. Each conjoint choice-set with its three stimuli represents a different possible purchase decision. Based on the total number of characteristics of each attribute, the total number of theoretically possible different stimuli can be calculated.

The total number of stimuli in our study equals $768(\mathrm{~N}=4 \times 4 \times 4 \times 3$ $\times 4=768$ ) because every attribute characteristic may be combined with every characteristic of the other attributes. As shown in Table 1, there are five different attributes in total. Every factor represents the quantity of characteristics of the respective attribute.

Out of the total 768 possible stimuli, 180 were selected for the survey following a symmetrical design. The "none" option was not included in the survey ("none" meaning not being interested in any electricity service at all), since we assumed that nobody would be willing to abstain completely from electricity use.

\section{Results and discussion}

The part-worth values described in Sect. 3.1 can be considered to be the most important empirical results of this study. They are complemented by the results of the clustering algorithms presented in Sect. 3.2. Section 3.3 summarizes our results.

\subsection{Part-worth values}

A potential smart meter service resulting from our study is composed of the characteristics of those five attributes (introduced in the previous section) that contribute to the total customer value. In accordance with Green and Srinivasan, we call the value that is added by a single attribute part-worth (Green and Srinivasan 1990). In Fig. 1, we present the part-worth utility function for each attribute and its particular characteristics. In a first step, we do not use a clustering algorithm and instead calculate the part-worth values for the total basic population of our questionnaire. The part-worth values were calculated based on the questionnaire 
Implications of customer value perceptions for the design...

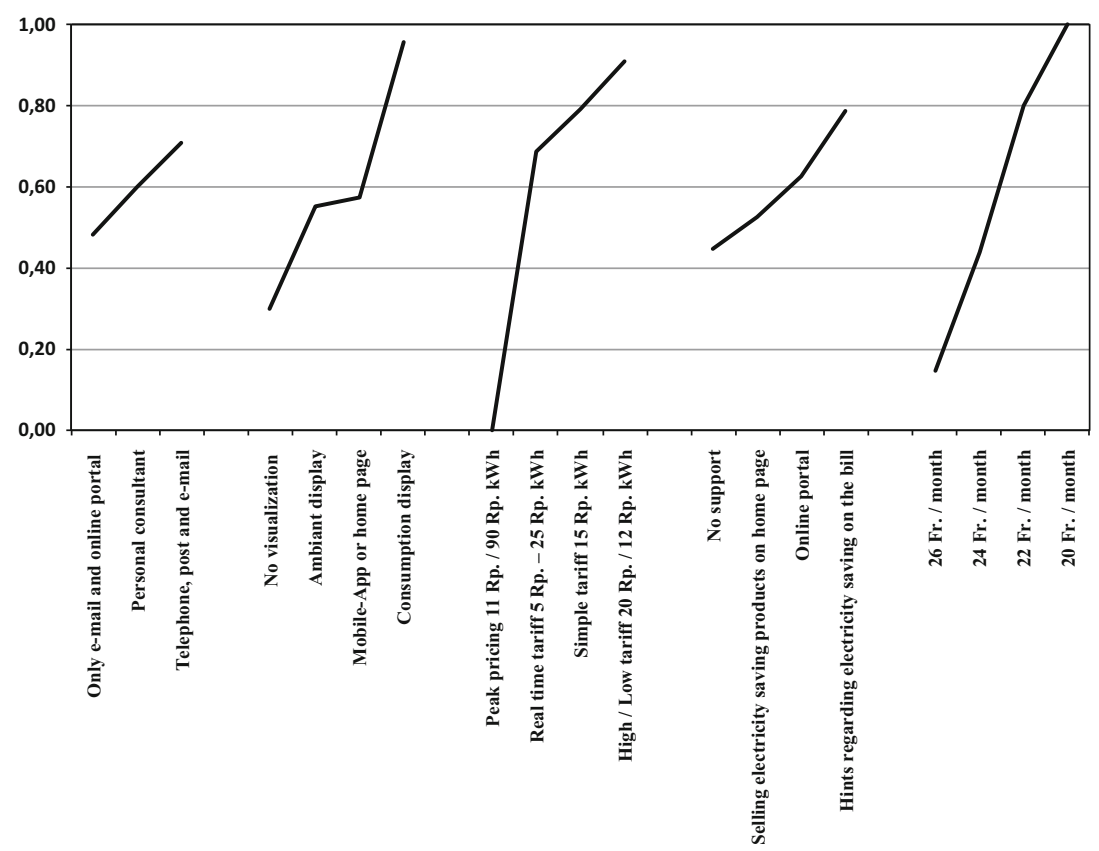

Fig. 1 Normalized part-worth values

data by logit estimation. To create groups, we use latent class analysis to calculate the part-worth values of the respondents for the multi-cluster solutions (Sect. 3.2) (Magidson et al. 2003). Because of the different characteristics an attribute may have, its part-worth values differ for each characteristic. In Fig. 1, on the $\mathrm{X}$ axis, the five attributes with their characteristics are presented. The impact of the attributes and their characteristics on the purchase decision are presented on the $\mathrm{Y}$ axis on a normalized basis. The part-worth values are arranged on an arbitrary linear scale and are not directly linked to currency units. We therefore use the attribute basic fee per month to enrich the pure utility values by currency units. The utility resulting from such enrichment is designated as "willingness to pay". Every part-worth value increase of 0.20 normalized points on the $\mathrm{Y}$ axis can be interpreted as the willingness to pay an additional 2.00 Fr. basic fee per month.

The attribute with the highest relative importance, as visualized by the biggest spread in Fig. 1, is the tariff model, which is responsible for $33 \%$ of the customer's purchase decision. A little less important is the basic fee per month attribute, with a $30 \%$ share. The exact values for these part-worth values are presented in Table 2. The utility of the price of the basic fee per month attribute declines linearly with the price level. This means that the different price levels have an equal impact on the customer's purchase decision. The tariff model characteristics are linearly connected, but the part-worth value of the peak pricing is much lower compared to the others. This shows that the peak pricing is the least favored pricing option of 
Table 2 Total part-worth values

\begin{tabular}{|c|c|c|c|c|}
\hline Attributes & Characteristics & $\begin{array}{l}\text { Average part-worth utilities } \\
\text { (rescaled for comparability) }\end{array}$ & $\begin{array}{l}\text { Standard } \\
\text { error }\end{array}$ & $\mathrm{t}$ ratios \\
\hline \multirow[t]{4}{*}{ Tariff model } & $\begin{array}{l}\text { High/low tariff (20 Rp. }{ }^{\mathrm{a}} / 12 \\
\text { Rp. kWh) }\end{array}$ & 52.75 & 0.020 & 16.69 \\
\hline & $\begin{array}{l}\text { Peak pricing (18 Rp./90 Rp. } \\
\text { kWh) }\end{array}$ & -112.13 & 0.026 & -27.85 \\
\hline & Simple tariff (19 Rp. kWh) & 37.61 & 0.022 & 11.21 \\
\hline & $\begin{array}{l}\text { Real time tariff (5 Rp. }-25 \\
\text { Rp. kWh) }\end{array}$ & 21.77 & 0.022 & 6.50 \\
\hline \multirow{4}{*}{$\begin{array}{c}\text { Electricity } \\
\text { savings } \\
\text { support }\end{array}$} & Online portal & 0.93 & 0.022 & 0.27 \\
\hline & $\begin{array}{l}\text { Selling electricity saving } \\
\text { products on home page }\end{array}$ & -14.74 & 0.023 & -4.16 \\
\hline & $\begin{array}{l}\text { Hints regarding electricity } \\
\text { savings on the bill }\end{array}$ & 33.55 & 0.022 & 9.62 \\
\hline & No support & -19.74 & 0.023 & -5.50 \\
\hline \multirow{4}{*}{$\begin{array}{l}\text { Electricity } \\
\text { monitor }\end{array}$} & Consumption display & 56.41 & 0.021 & 17.21 \\
\hline & Ambient display & -8.37 & 0.022 & -2.47 \\
\hline & Mobile-app or home page & -3.61 & 0.023 & -1.01 \\
\hline & No visualization & -44.43 & 0.022 & -13.06 \\
\hline \multirow{3}{*}{$\begin{array}{l}\text { Communication } \\
\text { channel }\end{array}$} & Telephone, post and e-mail & 12.53 & 0.017 & 4.66 \\
\hline & $\begin{array}{l}\text { Only e-mail and online } \\
\text { portal }\end{array}$ & -16.37 & 0.017 & -6.12 \\
\hline & Personal consultant & 3.84 & 0.017 & 1.48 \\
\hline \multirow{4}{*}{$\begin{array}{l}\text { Basic fee per } \\
\text { month }\end{array}$} & $20 \mathrm{Fr}$. & 75.69 & 0.021 & 23.42 \\
\hline & 22 Fr. & 29.61 & 0.022 & 8.68 \\
\hline & 24 Fr. & -28.92 & 0.023 & -8.03 \\
\hline & 26 Fr. & -76.38 & 0.024 & -20.68 \\
\hline
\end{tabular}

${ }^{a} 100$ Rp. $=1$ Fr. (Swiss Franc); 1Fr. is approximately worth $1 \$$ or $0.89 €$

the available tariffs, whereas the high/low tariff is the most favored. The tariffs of the tariff models (e.g., $11 \mathrm{Rp}=0.11 \mathrm{Fr}$. and $90 \mathrm{Rp}=0.90 \mathrm{Fr}$. in the peak pricing tariff) were selected in such a way that customers who do not change their behavior would pay the same amount of money for their electricity consumption independent of the tariff model selected. However, tariff models such as the peak pricing or the real time pricing models have a much higher inherent risk of leading to a higher electricity bill, and, therefore, they were found to be the least favored models.

On the other hand, for customers who want to change their behavior in order to save electricity, these are the specific tariffs that enable cost reductions. Additionally, by means of such tariff models, utilities can optimize their business and save money. This allows for offering cheaper tariff models to customers. However, such savings were not considered in the questionnaire in order to avoid influencing the customers. While the attributes electricity monitor and electricity savings support have an impact share on the customer's purchase decision of 20 and 
$11 \%$, respectively, the communication channel attribute has the lowest overall impact on the purchase decision (6\%). The customer answers regarding electricity monitor, by means of visualization displays, were as expected. The "no visualization" option was found to have the smallest utility. A consumption display that is able to visualize the electricity consumed in real time was found to have the highest perceived value. The ambient display and the mobile-app have almost equal values.

\subsection{Analysis of cluster results}

Based on the gathered data, we further analyze whether differences exist in consumer preferences. Therefore, we use a clustering algorithm to create customer segments. Such a clustering can yield further insights into the market, enable a better understanding of customer preferences, and create the foundation for understanding how to influence individuals in their smart metering technology acceptance. Due to the large sample size, we were able to reach very low standard errors (in the region of 0.02 , as shown in Table 2), resulting in differences between clusters that are statistically significant.

We used latent class analysis as a clustering algorithm, which is, according to Magidson et al. (2003), currently the best option to cluster choice-based conjoint data.

To determine the number of clusters to be used for our analysis, we calculated the values of three statistical indicators: the Akaike's information criterion (AIC), the consistent Akaike's (CAIC) information criterion, and the Bayesian information criterion (BIC) (Sawtooth Software Inc 2007). The optimal number of clusters is indicated by the minimal values of the metrics, as exhibited in Table 3. Two metrics indicate that five clusters can be considered to be the optimal number of clusters for the underlying data set. The AIC does not find its minimum within the eight clustering solutions and therefore was not considered.

In the next step, we calculated the relative importance of every attribute for the solution with five clusters. The results of the clustering procedure are presented in Fig. 2. The corresponding data details can be found in Table 4 .

Based on the identified clusters, we analyzed the data of the customers within the single clusters in order to understand their preferences. As illustrated in Fig. 2 the

Table 3 Segmentation criteria

\begin{tabular}{llll}
\hline Number of clusters & AIC & CAIC & BIC \\
\hline 1 & 17704 & 17817 & 17803 \\
2 & 17253 & 17488 & 17459 \\
3 & 16982 & 17339 & 17295 \\
4 & 16877 & 17356 & 17297 \\
$\mathbf{5}$ & 16716 & $\mathbf{1 7 3 1 7}$ & $\mathbf{1 7 2 4 3}$ \\
6 & 16626 & 17348 & 17259 \\
7 & 16547 & 17391 & 17287 \\
8 & 16498 & 17464 & 17345 \\
\hline
\end{tabular}




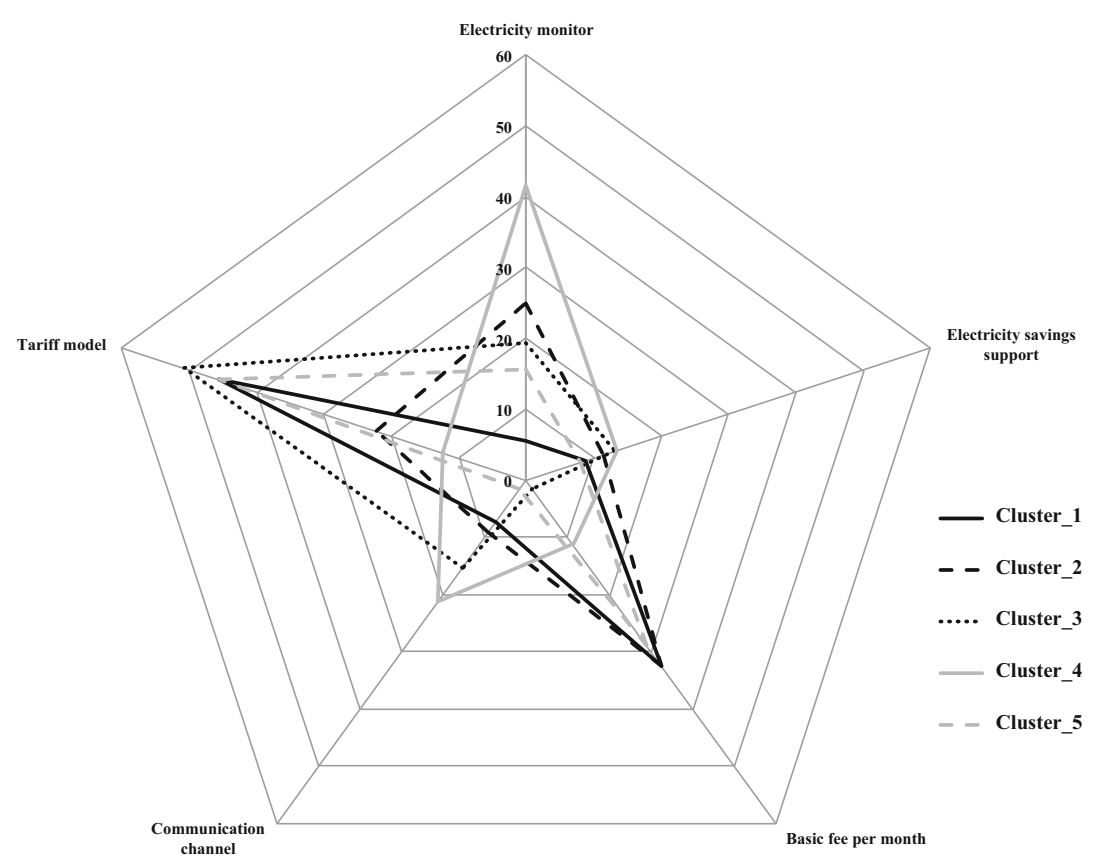

Fig. 2 Attributes' importance for the respondents of the five clusters

Table 4 Relative importance of attributes per cluster

\begin{tabular}{lccccc}
\hline Attributes $^{\mathrm{a}}$ & $\begin{array}{l}\text { Cluster 1 } \\
22.1 \% \\
\mathrm{n}=352\end{array}$ & $\begin{array}{l}\text { Cluster 2 } \\
19.5 \% \\
\mathrm{n}=311\end{array}$ & $\begin{array}{l}\text { Cluster 3 } \\
19.1 \% \\
\mathrm{n}=305\end{array}$ & $\begin{array}{l}\text { Cluster 4 } \\
13.8 \% \\
\mathrm{n}=220\end{array}$ & $\begin{array}{l}\text { Cluster 5 } \\
25.5 \% \\
\mathrm{n}=406\end{array}$ \\
\hline Communication channel & $7.40 \%$ & $9.20 \%$ & $15.40 \%$ & $\mathbf{2 1 . 3 0 \%}$ & $1.70 \%$ \\
Electricity monitor & $5.50 \%$ & $\mathbf{2 4 . 9 0 \%}$ & $\mathbf{1 9 . 2 0} \%$ & $\mathbf{4 1 . 5 0 \%}$ & $15.70 \%$ \\
Tariff model & $\mathbf{4 5 . 6 0 \%}$ & $22.10 \%$ & $\mathbf{5 0 . 8 0 \%}$ & $12.40 \%$ & $\mathbf{4 5 . 7 0 \%}$ \\
$\begin{array}{l}\text { Electricity savings } \\
\text { support }\end{array}$ & $8.70 \%$ & $11.40 \%$ & $13.10 \%$ & $13.50 \%$ & $8.00 \%$ \\
Basic fee per month & $\mathbf{3 2 . 7 0 \%}$ & $\mathbf{3 2 . 4 0 \%}$ & $1.50 \%$ & $11.30 \%$ & $\mathbf{2 8 . 9 0 \%}$ \\
\hline
\end{tabular}

${ }^{\mathrm{a}}$ The most important two attributes are highlighted in bold numbers

customer preferences across the five clusters are different. While the two most important attributes of clusters 1 and 5 are quite similar, the respondents of cluster 5 are much more interested in electricity monitors and less interested in communication channels. The respondents of clusters 2, 3 and 4 have very different attribute preferences. In particular, cluster 2 respondents consider the basic fee and the electricity monitors to be most relevant. The purchasing decision of the respondents of cluster 3 is highly dependent on the tariff model, which accounts for half of the decision, followed by the electricity monitor. It is interesting that the customers of 
this cluster do not take the basic fee into consideration (only a $1.5 \%$ attribute importance). Respondents of cluster 4 are the only ones who do not have a primary focus on pricing (neither on tariff model nor on the basic fee). Instead, these respondents are interested in electricity monitors and communication channels.

The relative importance of the five attributes per cluster is an interesting step towards a better understanding of customer preferences. Additional insights are provided by the part-worth values, which are presented as being similar to the basic population values, as shown in Fig. 1. The values for clusters 1-3 are shown in Fig. 3a, while the results of clusters 4 and 5 are presented in Fig. $3 b$.

In order to enable an easy comparison between the cluster results, the characteristics of the attributes have been listed in both figures in the same order. This resulted in the zig-zag lines for the attribute characteristics. The zig-zag line of the basic fee per month of cluster 4 is a typical example of the low importance of the said attribute: cluster 4 respondents have no clear price sensitivity in the given price range. The part-worth values of the five clusters create the basis for the derivation of customer segments and are presented in Sect. 3.3.

\subsection{Major results}

Based on the stated preferences as presented in Fig. 3a and b, we derive the following customer segments:

\subsubsection{Segment 1: price-sensitive (cluster 1)}

The most relevant attributes for customers in this segment are the tariff model and the basic fee. The strong impact of the high/low tariff show the readiness of the customers in this segment to adapt their behavior to save electricity. The price and tariff models play the most important role.

\subsubsection{Segment 2: technology-affine (cluster 2)}

The attribute characteristics with the highest impact within this customer segment are related to technology. The preferred communication channels of these customers are only e-mail and the online portal. The mobile-app or homepage is the preferred characteristic of the "electricity monitoring" attribute. The attribute characteristics with the largest impact on the purchase decision are peak pricing and "mobile-app or homepage" to monitor electricity consumption. This leads us to the conclusion that the customers within this segment are willing to change their attitude regarding electricity savings.

\subsubsection{Segment 3: comfort-oriented (cluster 3)}

Customers in this segment have a very low price sensitivity and prefer comfortable service characteristics, such as a personal consultant as a preferred communication channel. They prefer hints regarding electricity savings to be printed on the bill, as well as a simple tariff model. Even though customers in this 
A. Albani et al
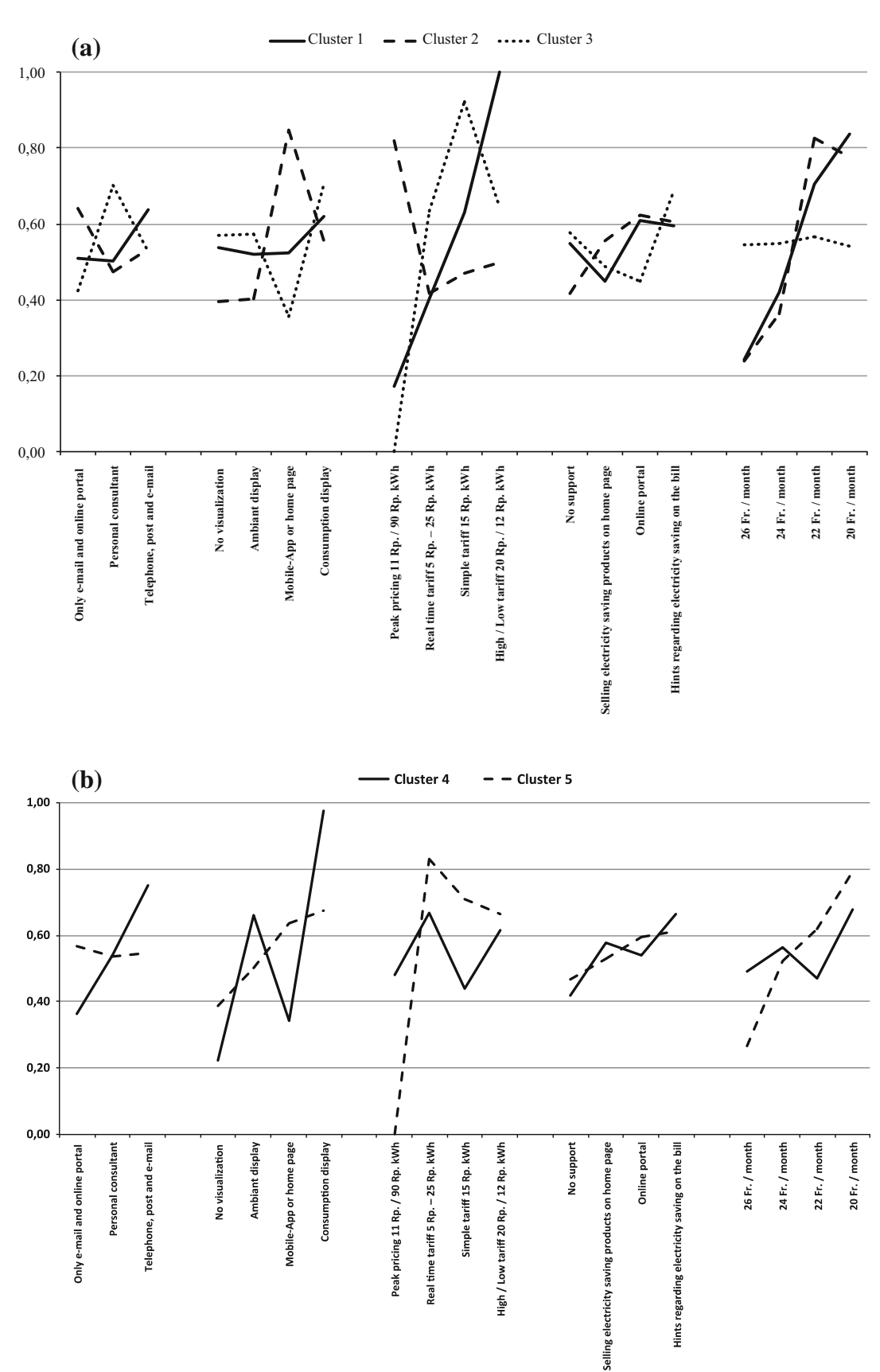

Fig. 3 a Part-worth values of clusters 1, 2, and 3. b Part-worth values of clusters 4 and 5

Springer 
segment are interested in consumption displays, their preferred tariff is the simple tariff. This clearly shows that these customers have a lower willingness to change their behavior and save electricity. One could also say that these customers are inflexible and cannot adapt their usage to dynamic tariffs.

\subsubsection{Segment 4: early adopter (cluster 4)}

The characteristic with the highest impact on the purchase decision is the consumption display. Combined with the real time tariff and price sensitivity, we conclude that customers in this segment are willing to apply smart meter technology and change their behavior. Furthermore, the importance of the service channel has the second most significant impact on the purchase decision for these customers. This supports our conclusion, because advice and support regarding how to change one's individual behavior in order to save electricity seems to be a very important aspect for early adopters.

\subsubsection{Segment 5: self-managed (cluster 5)}

Customers in the self-managed segment value the two attributes tariff model and basic fee most. The visualization of electricity consumption by using a monitor is also an important purchase incentive for these customers. Since the strongest characteristic is real time pricing, we conclude that these customers are willing to change their behavior in accordance with the current market developments of the electricity market. The electricity monitor can be used to inform customers about current market prices. This could be the reason why self-managed costumers are interested in electricity monitors.

From the analysis of these five customer segments, we can learn that there is only one segment (namely, the comfort-oriented segment, cluster 3) whose individuals are not significantly willing to change their behavior under the given conditions and pricing restrictions of our questionnaire.

\section{Implications for the design of smart meter-enabled energy efficiency services}

Based on our experience, we conclude that most electricity customers can be motivated to increase energy efficiency enabled by smart meter technology if appropriate tariff models, electricity monitors, communication channels, electricitysaving support hints or price changes are provided, depending on customer preferences. In this regard, we support and extend the results of the explorative survey of (Kaufmann et al. 2013).

The most promising service configurations resulting from the analysis of the customer preferences and their segmentations were derived for each segment, and implications for the design of smart meter-based services were proposed. When we talk about a promising service configuration, it is important to keep in mind that the questionnaire can reveal only the stated preferences of people. In the real world, 
A. Albani et al

Table 5 Promising service configurations for the customer segments

\begin{tabular}{|c|c|c|c|c|c|}
\hline & $\begin{array}{l}\text { Cluster 1: } \\
\text { price- } \\
\text { sensitive }\end{array}$ & $\begin{array}{l}\text { Cluster 2: } \\
\text { technology- } \\
\text { affine }\end{array}$ & $\begin{array}{l}\text { Cluster 3: } \\
\text { comfort- } \\
\text { oriented }\end{array}$ & $\begin{array}{l}\text { Cluster 4: early } \\
\text { adopter }\end{array}$ & $\begin{array}{l}\text { Cluster 5: self- } \\
\text { managed }\end{array}$ \\
\hline $\begin{array}{l}\text { Communication } \\
\text { channel }\end{array}$ & $\begin{array}{l}\text { Telephone, } \\
\text { post and } \\
\text { email }\end{array}$ & $\begin{array}{l}\text { Only e-mail } \\
\text { and online }\end{array}$ & $\begin{array}{l}\text { Personal } \\
\text { consultant }\end{array}$ & $\begin{array}{l}\text { Telephone, post } \\
\text { and e-mail }\end{array}$ & $\begin{array}{l}\text { Only e-mail and } \\
\text { online portal }\end{array}$ \\
\hline $\begin{array}{c}\text { Electricity } \\
\text { monitor }\end{array}$ & $\begin{array}{l}\text { Consumption } \\
\text { display }\end{array}$ & $\begin{array}{l}\text { Mobile-app } \\
\text { or home } \\
\text { page }\end{array}$ & $\begin{array}{l}\text { Consumption } \\
\text { display }\end{array}$ & $\begin{array}{l}\text { Consumption } \\
\text { display }\end{array}$ & $\begin{array}{l}\text { Consumption } \\
\text { display }\end{array}$ \\
\hline Tariff model & $\begin{array}{l}\text { High/low } \\
\text { tariff } \\
20 \mathrm{Rp} . / 12 \mathrm{Rp} . \\
\mathrm{kWh}\end{array}$ & $\begin{array}{l}\text { Peak pricing } \\
18 \text { Rp./90 } \\
\text { Rp. kWh }\end{array}$ & $\begin{array}{l}\text { Simple tariff } \\
15 \text { Rp. kWh }\end{array}$ & $\begin{array}{l}\text { Real time tariff } \\
15 \text { Rp.-25 Rp. } \\
\text { kWh }\end{array}$ & $\begin{array}{l}\text { Real time tariff } \\
15 \mathrm{Rp} .-25 \mathrm{Rp} . \\
\text { kWh }\end{array}$ \\
\hline $\begin{array}{c}\text { Electricity } \\
\text { savings } \\
\text { support }\end{array}$ & Online portal & $\begin{array}{l}\text { Online } \\
\text { portal }\end{array}$ & $\begin{array}{l}\text { Hints regarding } \\
\text { electricity } \\
\text { saving on the } \\
\text { bill }\end{array}$ & $\begin{array}{l}\text { Hints regarding } \\
\text { electricity } \\
\text { saving on the } \\
\text { bill }\end{array}$ & $\begin{array}{l}\text { Hints regarding } \\
\text { electricity } \\
\text { saving on the } \\
\text { bill }\end{array}$ \\
\hline $\begin{array}{l}\text { Basic fee per } \\
\text { month }\end{array}$ & $20 \mathrm{Fr}$. & $20 \mathrm{Fr}$. & $20 \mathrm{Fr}$. & $20 \mathrm{Fr}$. & $20 \mathrm{Fr}$. \\
\hline
\end{tabular}

actual purchase decisions may be significantly different. Even though this approach leads to potential problems, it seems to be appropriate for obtaining a first impression of customer preferences before rolling out a service in the market.

The identified promising service configurations for the five customer segments are listed in Table 5.

Our study shows that the value of a service is closely related to a combination of the attributes. An exemplary combination would be a real time pricing usage fee together with a consumption display for the currently used electricity. Earlier studies support this conclusion by testing the impact of enabling technology on the effectiveness of usage fees (Faruqui and George 2005; Faruqui et al. 2009, 2010). From our perspective, the most preferred services presented in this paper should be implemented by smart metering information systems and offered by energy providers to customers in order to maximize the electricity efficiency potential to be realized.

Besides these basic decisions that influence the initial adoption intention and the perceived value of enabling smart meter services, in the end, their continuous use will be crucial for the long-term effectiveness of electricity efficiency endeavors.

Based on this argumentation and on the lessons learned from the heterogeneity of the preferences of the respondents, we present our implications for the design of smart meter-enabled energy efficiency services next. However, we imply that the smart meters comply with a certain minimal technical specification in order to guarantee that the different services, as identified for the different customer segments, can be offered to customers via smart meter information systems.

Summarizing the outcomes of the study regarding the communication channel attribute characteristics, we can state that each communication channel is preferred 
by at least one customer segment. It is therefore important to use all channels-in other words, not only traditional telephone, mail, and personal consulting channels but also online portals and e-mail channels need to be used in order to reach as many customers as possible. This means that smart meter-based services should offer a choice between offline and online communication channels to provide electricity savings support. The channels are not necessarily exclusive and may be used in parallel in order to increase the desired effects. Further, the visualization of electricity consumption is the fundamental basis for consumption awareness and is therefore highly relevant for a potential change of customer behavior. Three customer segments valued the electricity monitor attribute as one of the most important attributes. The monitor makes electricity consumption visible, which is otherwise very difficult to understand. The smart meter services should therefore offer visualization options of electricity consumption, which can be realized either by providing a consumption display or by using a mobile-app or a web page. In addition to the offering of awareness options of the electricity consumed, smart meter tariff models foster changes in customer behavior, allowing for cost and electricity savings. The following tariff models appeared to be highly relevant for the identified customer segments: peak pricing, real-time pricing, simple tariff and high/low tariff. As presented in the promising service configurations for the identified customer segments in Table 5, we suggest offering the high/low tariff to price-sensitive customers, peak-pricing to technology-affine customers, real time tariff to early adopters and self-managed customers, and the simple tariff to the comfort-oriented customers.

\section{Summary, limitations and research outlook}

This study analyzes the preferences of more than 1500 electricity customers in three regions of Switzerland. We focused on a choice-based conjoint analysis and found that the respondents rate the proposed smart meter services very differently. We identified five clusters with homogeneous preferences: price-sensitive, technologyaffine, comfort-oriented, early adopters, and self-managed customers. Except for the comfort-oriented segment, the customers in all other four segments (which account for $80.9 \%$ of all respondents) are willing to pay for smart meter services and to change their behavior. However, the types of services in which these customers are interested differ widely. The two most contrarian segments are early adopters and comfort-oriented customers. Early adopters are willing to use new metering technology and the corresponding services. They are also very enthusiastic about changing their electricity consumption behavior. Based on the demographic data, we conclude that this segment contains, on average, the youngest customers. Comfort-oriented customers, in contrast, are not willing to use smart meter-enabled tariffs at all. Analyzing the demographic data of this segment, it becomes apparent that this segment contains the oldest respondents on average.

Even though we built upon existing work and followed a rigorous approach, this study is subject to certain limitations. First, the questionnaires were distributed in Switzerland only. However, we assume that the results of the questionnaire can be 
used on a more generic level in other countries-in particular, in countries where smart grid appliances have not yet been rolled out.

Second, the questionnaire format could be a potential source of disagreement. We chose the paper-based format in order to avoid the negative biases that a pure online survey has, but we are well aware that such a format might lead to negative biases. Because of a restricted number of questionnaire versions, the statistical quality of the results may suffer compared to an online questionnaire, where new choice sets may be easily provided for every respondent. Furthermore, the respondents may not be forced to select a choice set as with the online version. We tried to overcome these shortcomings by (1) generating ten versions of the questionnaire and thereby omitting the problem of the limited number of questionnaires and (2) by eliminating questionnaires from respondents with insufficient information.

Third, we used the latent class algorithm in order to calculate the optimal number of clusters. According to Magidson et al. (2003), this is the best-known way to calculate cluster values based on a choice-based conjoint questionnaire. However, future studies could apply alternative clustering algorithms. A comparison and analysis of the different clusters gained through different algorithms could be of interest for future work in order to further improve the customer segmentation as a basis for more detailed smart meter service requirements.

Fourth, our respondents did not really buy services - their choices are hypothetical and not real. In reality, deviations between stated preferences and real purchases may occur. The respondents tend to answer questionnaires as they think a rational third party would do, especially if they want to see themselves as better people. However, particularly through the use of the choice-based conjoint analysis, the respondents' answers usually come quite close to real purchase decisions. However, the answers remain hypothetical and the data are affected by this bias.

Fifth, the attribute electricity savings support was included in the questionnaire in order to provide different options for the respondents to obtain information about energy efficiency measures. It is possible that part of the customers will need this service only for a short period of time, since once they learn how to save energy, there is no further need for additional saving hints. However, we assumed that continuous information about how to save energy is important and regarded this attribute therefore as relevant for the study.

Finally, the intention to continuously use smart grid appliances has not been addressed in this study. For all services, the value perceived by customers is a crucial factor for adoption intention as well as for continuous use (Kim et al. 2007; Kuo et al. 2009). As stated by Jasperson et al. (2005) and Larsen et al. (2009), continuous use will play a major role in the smart grid domain. However, we cannot analyze continuous use aspects yet, because smart meter technology has not yet been rolled out broadly in Switzerland. Furthermore, comparisons with other countries might not be useful due to several significant contextual differences, such as different levels of energy dependence and different solar energy resources, such as in Spain (Colmenar-Santos et al. 2012). Instead, we focused on the value-based aspects of smart meter services for electricity customers that exhibit the impact of benefits and sacrifices on perceived customer value. It is clear that although initial 
adoption preferences are important, only continuous use of such appliances will lead to significant sustained changes in electricity consumption. Analyzing the interconnection between the adoption intention of and continuous use by the identified customer segments would be a further topic for future research. However, this can only be performed in a longitudinal study in which smart meters are used for a given period of time.

Acknowledgments This project is partially supported by the Swiss Commission for Technology and Innovation (CTI).

\section{References}

Baeriswyl M, Müller A, Rigassi R, Rissi C, Solenthaler S, Staake T, Weisskopf T (2012) Folgeabschätzung einer Einführung von «Smart Metering » im Zusammenhang mit «Smart Grids » in der Schweiz. http://www.news.admin.ch/NSBSubscriber/message/attachments/27519. pdf. Accessed 10 April 2013

Becker D, Wichmann J, Bader N (2012) Effizienzmodell für Schweizer Stromlieferanten. http://www.bfe. admin.ch/php/modules/publikationen/stream.php?extlang=de\&name=de_250779416.pdf. Accessed 6 Oct 2014

Colmenar-Santos A, Campíñez-Romero S, Pérez-Molina C, Castro-Gil M (2012) Profitability analysis of grid-connected photovoltaic facilities for household electricity self-sufficienc. Energy Policy 51(2012):749-764

Darby S (2006) The effectiveness of feedback on energy consumption. Oxford

Dellaert B, Borgers A, Timmermans H (1996) Conjoint choice models of joint participation and activity choice. Int J Res Mark 13(3):251-264

Directive/27/Eu (2012) Directive 2012/27/EU of the European Parliament and of the Council of 25 October 2012 on energy efficiency, amending directives 2009/125/EC and 2010/30/EU and repealing directives 2004/8/EC and 2006/32/EC text with EEA relevance

Ehrhardt-Martinez K, Donnelly KA, Laitner JA (2010) Advanced metering initiatives and residential feedback programs: a meta-review for household electricity-saving opportunities. Americal Council for an Energy-Efficient Economy, Washington

European Commission (2011) MEMO/11/440. Brussels

Faruqui A, George S (2005) Quantifying customer response to dynamic pricing. Electr J 18(4):53-63

Faruqui A, Sergici S (2008) The power of experimentation. San Francisco

Faruqui A, Hledik R, Sergici S (2009) Piloting the smart grid. Electr J 22(7):55-69

Faruqui A, Harris D, Hledik R (2010) Unlocking the $€ 53$ billion savings from smart meters in the EU: how increasing the adoption of dynamic tariffs could make or break the EU's smart grid investment. Energy Policy 38(10):6222-6231

Fischer C (2008) Feedback on household electricity consumption: a tool for saving energy? Energ Effic 1(1):79-104

Flath C, Nicolay D, Conte T, van Dinther C, Filipova-Neumann L (2012) Cluster analysis of smart metering data. WIRTSCHAFTSINFORMATIK 54(1):33-42

Goebel C, Jacobsen H-A, del Razo V, Doblander C, Rivera J, Ilg J, Lässig J (2014) Energy informaticscurrent and future research directions. Bus Inform Syst Eng 6(1):25-31

Green PE, Srinivasan V (1978) Conjoint analysis in consumer research: issues and outlook. J Consum Res 5(2):103-123

Green PE, Srinivasan V (1990) Conjoint analysis in marketing: new developments with implications for research and practice. J Market 54(4):3-19

Hair JF, Black WC, Babin BJ, Anderson RE (2009) Multivariate data analysis, 7th edn. Prentice Hall, Upper Saddle River

Jasperson J, Carter PE, Zmud RW (2005) A comprehensive conceptualization of post-adoptive behaviors associated with information technology enabled work Systems. MIS Q 29(3):525-557

Kaufmann S, Künzel K, Loock M (2013) Customer value of smart metering: explorative evidence from a choice-based conjoint study in Switzerland. Energy Policy 53:229-239 
Kim H-W, Chan HC, Gupta S (2007) Value-based adoption of mobile internet: an empirical investigation. Decis Support Syst 43(1):111-126

Kuan-Yu L, Hsi-Peng L (2011) Why people use social networking sites: an empirical study integrating network externalities and motivation theory. Comput Hum Behav 27(3):1152-1161

Kuo Y-F, Wu C-M, Deng W-J (2009) The relationships among service quality, perceived value, customer satisfaction, and post-purchase intention in mobile value-added services. Comput Hum Behav 25(4):887-896

Larsen TJ, Sørebø AM, Sørebø Ø (2009) The role of task-technology fit as users' motivation to continue information system use. Comput Hum Behav 25(3):778-784

Loock M, Staake T, Thiesse F (2013) Motivating energy-efficient behavior with green IS: an investigation of goal setting and the role of defaults. MIS Q 37(4):1313-1332

Louviere JJ (1988) Analyzing decision making: metric conjoint analysis

Mack B (2007) Energiesparen fürdern durch psychologische intervention. Waxmann Verlag, New York

Magidson J, Eagle T, Vermunt JK (2003) New developments in latent class choice models. In: Sawtooth Software Conference Proceedings

Malhotra A, Melville NP, Watson RT (2013) Special issue: spurring impactful research on information systems for environmental sustainability. MIS Q Manag Inform Syst 37(4):1265-1274

Messerschmidt CM, Lilienthal M, Skiera B (2010) The utility of TAM-perceptions: integration of technology perceptions into choice-based conjoint analysis. ACIS, Thiruvananthapuram

Muench S, Thuss S, Guenther E (2014) What hampers energy system transformations? The case of smart grids. Energy Policy 73:80-92

Nachreiner M, Mack B, Matthies E, Tampe-Mai K (2015) An analysis of smart metering information systems: a psychological model of self-regulated behavioural change (to be published). Energy Res Soc Sci 9:85-97

Owen HH (2008) Open space technology: a user's guide, 3rd edn. ReadHowYouWant, San Francisco

Römer B, Reichhart P, Kranz J, Picot A (2012) The role of smart metering and decentralized electricity storage for smart grids: the importance of positive externalities. Energy Policy 50:486-495

Sawtooth Software Inc (2007) Latent class v4. http://www.sawtoothsoftware.com/download/ssiweb/ LClass_Manual.pdf. Accessed 16 Nov 2012

vom Brocke J, Simons A, Niehaves B, Riemer K, Plattfaut R, Cleven A (2009) Reconstructing the giant: on the importance of rigour in documenting the literature search process. In: Paper presented at the 17 th European conference on information systems, Verona 